\title{
Growth promotion and colonization of switchgrass (Panicum virgatum) cv. Alamo by bacterial endophyte Burkholderia phytofirmans strain PsJN
}

\author{
Seonhwa Kim', Scott Lowman ${ }^{1,2}$, Guichuan Hou ${ }^{4}$, Jerzy Nowak ${ }^{2}$, Barry Flinn ${ }^{1,2,3}$ and Chuansheng Mei ${ }^{1,2,3^{*}}$
}

\begin{abstract}
Background: Switchgrass is one of the most promising bioenergy crop candidates for the US. It gives relatively high biomass yield and can grow on marginal lands. However, its yields vary from year to year and from location to location. Thus it is imperative to develop a low input and sustainable switchgrass feedstock production system. One of the most feasible ways to increase biomass yields is to harness benefits of microbial endophytes.

Results: We demonstrate that one of the most studied plant growth promoting bacterial endophytes, Burkholderia phytofirmans strain PsJN, is able to colonize and significantly promote growth of switchgrass $\mathrm{Cv}$. Alamo under in vitro, growth chamber, and greenhouse conditions. In several in vitro experiments, the average fresh weight of PsJN-inoculated plants was approximately $50 \%$ higher than non-inoculated plants. When one-month-old seedlings were grown in a growth chamber for 30 days, the PsJN-inoculated Alamo plants had significantly higher shoot and root biomass compared to controls. Biomass yield (dry weight) averaged from five experiments was $54.1 \%$ higher in the inoculated treatment compared to non-inoculated control. Similar results were obtained in greenhouse experiments with transplants grown in 4-gallon pots for two months. The inoculated plants exhibited more early tillers and persistent growth vigor with $48.6 \%$ higher biomass than controls. We also found that PsJN could significantly promote growth of switchgrass cv. Alamo under sub-optimal conditions. However, PsJN-mediated growth promotion in switchgrass is genotype specific.

Conclusions: Our results show B. phytofirmans strain PsJN significantly promotes growth of switchgrass CV. Alamo under different conditions, especially in the early growth stages leading to enhanced production of tillers. This phenomenon may benefit switchgrass establishment in the first year. Moreover, PsJN significantly stimulated growth of switchgrass cv. Alamo under sub-optimal conditions, indicating that the use of the beneficial bacterial endophytes may boost switchgrass growth on marginal lands and significantly contribute to the development of a low input and sustainable feedstock production system.
\end{abstract}

Keywords: Bacterial endophyte, Burkholderia phytofirmans strain PsJN, Colonization, Growth promotion, Biomass increase, Switchgrass cv. Alamo

\footnotetext{
* Correspondence: chuansheng.mei@ialr.org

${ }^{1}$ Institute for Sustainable and Renewable Resource, Institute for Advanced

Learning and Research, 150 Slayton Ave, Danville, VA 24540, USA

${ }^{2}$ Department of Horticulture, Virginia Polytechnic Institute and State

University, Blacksburg, VA 24601, USA

Full list of author information is available at the end of the article
} 


\section{Background}

Increasing concern over foreign energy supplies, global greenhouse gas emissions and the need for rural economic development has driven the interest in sustainable biomass production for bioenergy and bio-products. It has been suggested that by 2025 , the world energy demand will likely be increased by more than $50 \%[1,2]$. This demand, and societal concerns about the environmental impact of burning fossil fuels are key factors stimulating the development of national and regional strategies aimed at the growth of renewable energy supplies, primarily focused on biofuels. To reduce the reliance on fossil fuels, the USA, the world's major energy consumer, released the Energy Independence and Security Act of 2007 that aims to increase the production of renewable fuels from 9.0 billion gallons in 2008 to 36 billion gallons by 2022 [3]. The recent USDA/DOE National Biofuels Action Plan [4] has helped to delineate the priority areas required to accelerate sustainable biofuel industry development. Within this document, Action Area 2 was identified as feedstock production and improvement. Various feedstocks, such as perennial rhizomatous grasses, can provide sources of lignocellulosic biomass, serving as new sources of crop growth and income for regional farmers.

One of the most promising feedstocks capable of contributing to the realization of US renewable energy goals is the common perennial grass, switchgrass (Panicum virgatum L.) [5]. This native prairie grass, consisting of a diverse germplasm [6], can grow on marginal lands under low inputs of water and agrochemicals [7], so that its cultivation does not compete with food crops for land and other resources. Due to its large root system and fast stand regrowth, switchgrass has other positive environmental effects, including the prevention of surface runoff and soil erosion, carbon sequestration, and the provision of a wildlife habitat $[5,8]$. Switchgrass cultivated lands also had much higher total soil organic carbon deposits than lands cultivated with annual crops, such as corn and wheat $[9,10]$.

The economics of biofuel production is highly dependent on feedstock cost and conversion technology $[1,6]$. The development of improved switchgrass varieties for lowcost production on marginal lands is one prerequisite for the success of the bioenergy program [5,11]. One such approach involves the use of beneficial microorganisms, such as endophytes, which form intimate associations with plants $[12,13]$. Endophytes, both fungal and bacterial, have been targeted as mechanisms to enhance plant characteristics for commercial uses [14]. The colonization of grasses by fungal endophytes for performance enhancement is well documented [15], including their use with switchgrass $[16,17]$. However, to our knowledge, only one study has reported growth promotion of a bioenergy feedstock grass (Miscanthus x giganteous) seedlings by a bacterial endophyte (Herbaspirillum frisingense) [18]. A key component of our bioenergy crop research program involves the utilization of beneficial bacterial endophytes that form stable and persistent associations with switchgrass, as the mechanism to improve biomass yield and enhance stress tolerance under low-input production systems [19]. Beneficial bacterial endophytes are naturally occurring soil microorganisms that can penetrate plant roots and translocate to the above ground organs and, upon colonization, affect plant growth, health, and productivity [12,20-22]. Although the molecular mechanisms of beneficial endophyte-host plant interactions are largely unknown, several studies have demonstrated that endophytes can promote plant growth by enhancing the plant's capacity for nutrient acquisition, better water management, and/or resistance to abiotic and biotic stresses via regulation of hormones [12-14,20,21]. For instance, 1-aminocyclopropane-1-carboxylic acid (ACC) deaminase produced by endophytes lowers the ethylene levels in host plants, reducing their response to abiotic and biotic stress, and by changing root morphology, leading to stimulation of plant growth $[13,23,24]$. Many known endophytes also promote plant growth by producing gibberellic acid $\left(\mathrm{GA}_{3}\right)$, indole3 -acetic acid (IAA) [18,25], or cytokinins [26,27].

Burkholderia phytofirmans strain PsJN has been found to be a highly effective plant growth promoting bacterial endophyte, with a broad host range including potatoes, tomatoes, and grape vines [21,27-32]. In addition, its genome has recently been sequenced [33], providing the genomic resources needed to develop an understanding of the mechanisms associated with this endophyte's ability to promote plant growth. PsJN produces a high level of ACC deaminase [31], enhances host plant cold [34] and heat [35] stress tolerance, improves water management [36] and plant resistance to pathogens $[37,38]$. In this study, we report growth promotion of switchgrass cv. Alamo by Burkholderia phytofirmans strain PsJN under in vitro, growth chamber, and greenhouse conditions. To our knowledge, this is the first report detailing the switchgrass-PsJN interaction.

\section{Results}

PsJN endophytic association with switchgrass Alamo

The endophytic colonization of switchgrass by Burkholderia phytofirmans strain PsJN-GFP was visualized using confocal microscopy (Figure 1). Under the appropriate illumination, the PsJN-GFP could be clearly observed inside the roots of PsJN-inoculated plants 3 days after inoculation, while no fluorescence was observed in roots of buffer-inoculated control plants. The titer of PsJNGFP in inoculated plants was also determined using tissue homogenates from various tissues (root, leaf and 


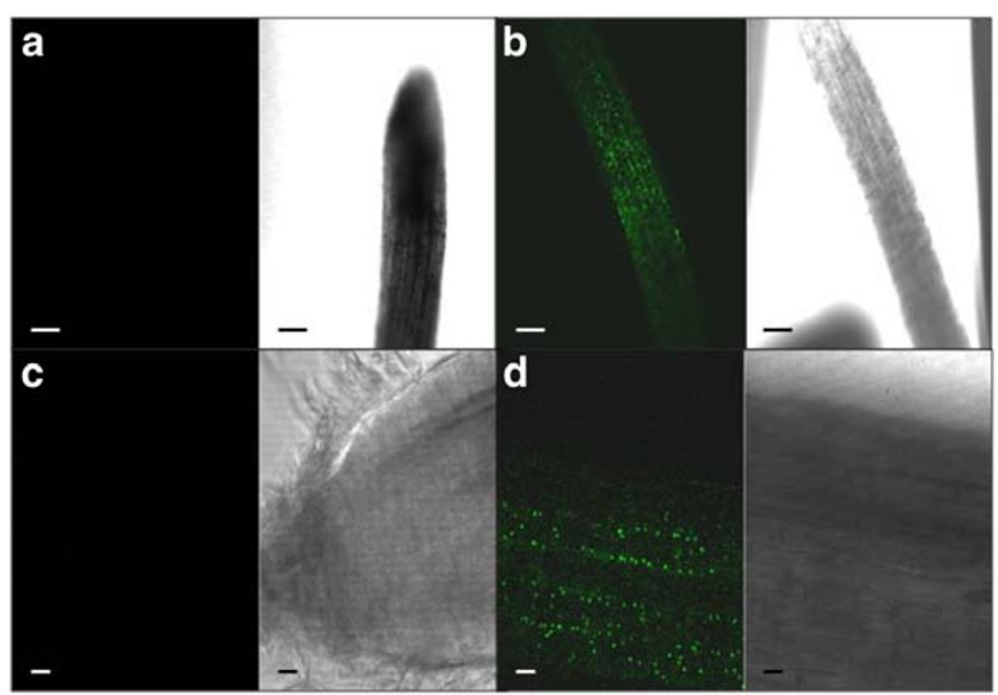

Figure 1 Confocal images of roots taken 3 days following switchgrass cv. Alamo inoculation with PsJN-GFP, showing bacterial colonization inside the roots. (A): Control and (B): PsJN-inoculated plants. (C): Control and (D): PsJN-inoculated plants. In each section (a,b,c,d), left panels were observed under fluorescent light and right panels under visible light. The bars represent $100 \mu \mathrm{m}(\mathrm{A}$ and B) and $20 \mu \mathrm{m}(\mathrm{C}$ and D).

sheath) at different times (Table 1). The endophyte initially infected and colonized plant roots, and by 7 days post-inoculation, PsJN titers were still highest in the root. However, the titers increased significantly in other tissues by day 14, indicating translocation to leaves and sheaths.

\section{Effects of PsJN on Alamo growth in vitro}

Young switchgrass seedlings were prepared and inoculated as described in Materials and Methods, and the non-inoculated and inoculated plants were analyzed after growth in vitro for one month. The result showed that PsJN significantly and repeatedly promoted Alamo root and shoot growth, with a $35.6 \%$ increase in shoot length, a $32.8 \%$ increase in root length, and an $83.6 \%$ increase in fresh weight, compared to the non-inoculated plants (Figure 2). After several replications, the average fresh weight of the PsJN-inoculated plants was always approximately $50 \%$ higher than non-inoculated plants.

\section{Table 1 Colony-forming units (CFU) of root, leaf, and sheath tissues at different times after PsJN-GFP inoculation}

\begin{tabular}{lll}
\hline $\begin{array}{l}\text { Days after PsJN- } \\
\text { GFP inoculation }\end{array}$ & Plant tissues & $\begin{array}{l}\text { Average CFU/g } \\
\text { Fresh weight }\end{array}$ \\
\hline 3 & All (Roots, leaves, and sheath) & $4.2 \times 10^{5}$ \\
7 & Roots & $7.6 \times 10^{5}$ \\
& Leaves & $2.6 \times 10^{3}$ \\
14 & Roots & $3 \times 10^{4}$ \\
& Sheaths & $1.3 \times 10^{5}$ \\
& Leaves & $1.2 \times 10^{5}$ \\
\hline
\end{tabular}

Effects of PsJN on Alamo growth in a growth chamber environment

As described above, PsJN significantly enhanced switchgrass cv. Alamo growth in vitro. We next assessed the impact of PsJN on growth under soil conditions. One-monthold in vitro grown Alamo (control and PsJN-inoculated seedlings) were transferred to a flat with 72 cavities filled with soil and grown in a growth chamber under $28 / 22^{\circ} \mathrm{C}$ day/night temperatures with $16 \mathrm{~h}$ light period for one month. The PsJN-inoculated plants showed significant growth increases compared to control plants in shoot length and fresh/dry weights (Figure 3). The growth chamber experiments were repeated 5 times, and the average data from 5 experiments showed significant growth promotion by PsJN, with a $46.3 \%$, and a $54.1 \%$ increase in fresh weight and dry weight, respectively. The total dry weight increase $(54.1 \%)$ by PsJN was more than the total fresh weight increase (46.3\%), indicating that the PsJNinoculated plants accumulated more biomass.

\section{Effects of PsJN on Alamo growth in the greenhouse}

Non-inoculated and PsJN-inoculated plants were also grown under greenhouse conditions to determine growth enhancement persistence. The plants inoculated with PsJN and grown in vitro for 25 days were transferred to 4-gallon pots with 5 plants in each pot and grown in the greenhouse. The plants inoculated with PsJN exhibited sustained growth vigor, as they were significantly taller, and more tillers developed early compared with the non-inoculated control plants (Figure 4). Following one month of growth in the greenhouse, the PsJN-inoculated plants had 76.2\% more tillers than the control plants. The plants were 

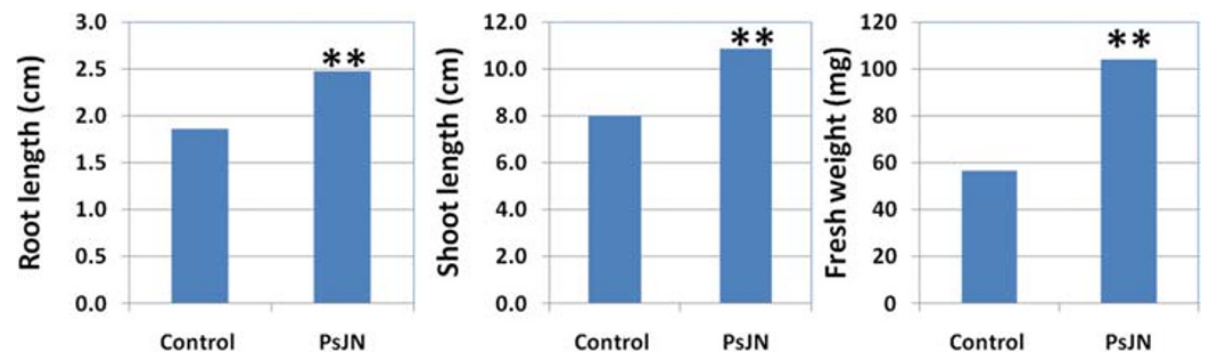

Figure 2 Effects of endophyte PsJN inoculation on switchgrass cv. Alamo growth in vitro. Data were obtained after plants were grown in incubator for 36 days. Sample number was 25 , and ${ }^{* *}$ means significant difference at 0.01 level between PsJN and control using student $T$-test.

harvested following growth for two months, and the biomass yield determined (Figure 5). The PsJN-inoculated plants were repeatedly significantly higher in biomass yield, with a $36.8 \%$ increase in fresh weight and a $57.1 \%$ increase in dry weight.

\section{Effects of PsJN on Alamo growth in sub-optimal conditions} In order to develop a low input and sustainable switchgrass feedstock production system utilizing the beneficial bacterial endophyte, we tested growth performance of PsJN-inoculated plant with unfertilized field soil, in a glasshouse under ambient conditions during the Fall, when the temperature was not optimal for switchgrass growth. The results showed that PsJN-inoculated plants produced twice the total biomass of controls (Figure 6).

\section{Direct inoculation of switchgrass seeds with PsJN}

In order to explore a practical way to inoculate switchgrass with the bacterial endophyte, we sterilized switchgrass seeds as described in Materials and Methods, placed the sterilized seeds on wet filter paper for 3-5 days in an incubator at $25^{\circ} \mathrm{C}$, and then inoculated the germinating seeds with different concentrations of endophyte inoculum to determine the optimal inoculation concentration $\left(\mathrm{OD}_{600}\right.$ at $\left.0.1-0.5\right)$. The plants inoculated with PsJN at
$\mathrm{OD}_{600}$ of $0.1,0.25$, and 0.5 exhibited $28.7 \%, 55.0 \%$ and $80.1 \%$ increases in dry weight, respectively, compared to non-inoculated plants after grown in vitro for 25 days and in growth chamber for another month. A PsJN concentration of 0.5 was the most effective at promoting biomass increase (Figure 7), and no biomass difference was observed between the 0.1 treatment and control.

Endophyte infection and colonization of seeds are dependent on endophyte concentration and the status of seed imbibitions. So, in order to facilitate infection and colonization by the bacterial endophyte, the sterilized seeds were imbibed in water for $1,2,3$, or 4 days, and then inoculated with PsJN at an $\mathrm{OD}_{600}$ of 0.5 or 1.0, since an $\mathrm{OD}_{600}$ of 0.5 was the most effective as described above. The PsJN-inoculated seeds were placed in an incubator at $25^{\circ} \mathrm{C}$ with a $16 \mathrm{~h}$ light period for 25 days, and transferred to soil and grown in a growth chamber for 37 days. The results indicated that plants from the seeds imbibed for 2 days and then inoculated with an $\mathrm{OD}_{600}$ of 0.5 had the highest dry weight, with a $55 \%$ increase compared to non-inoculated control plants (Figure 8).

\section{Genotypic responses to PsJN}

As described above, PsJN was able to stimulate growth in switchgrass cv. Alamo. To assess the influence of
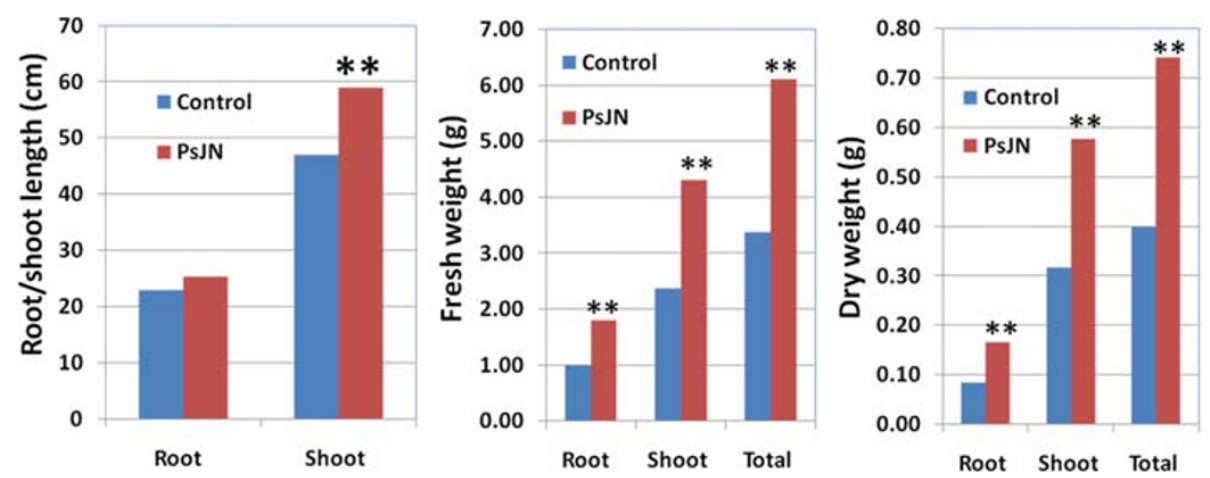

Figure 3 Effects of endophyte PsJN inoculation on switchgrass cv. Alamo growth in growth chamber. The seedlings were inoculated with PsJN and grown in vitro for one month, then transferred to soil and grown in growth chamber for another month. Dry weight was determined after samples were dried in oven at $65^{\circ} \mathrm{C}$ for one day. Sample number was 36, and ** means significant difference at 0.01 level between PsJN and control using student $T$-test. 

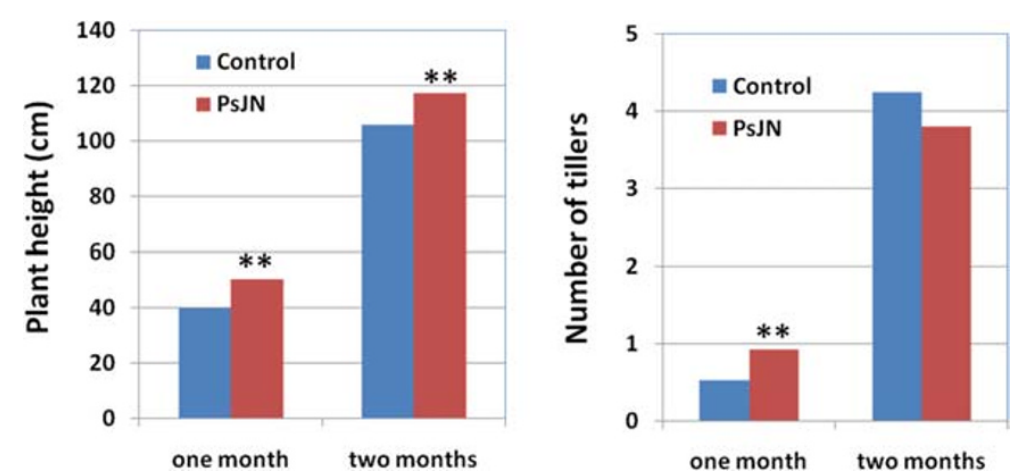

Figure 4 Plant growth and tiller development after control and PsJN inoculated plants were transferred to 4-gallon pots and grown in greenhouse.

plant genotype on this response, seven other switchgrass cultivars were tested for their growth responses to PsJN. As shown in Table 2, growth promotion by PsJN was genotype-dependent. The switchgrass cvs. Forestburg, Nebraska, and Blackwell were all responsive to PsJN, with measured significant growth increases of $60.1 \%$, $26.8 \%$, and $23.0 \%$, respectively, while the cvs. Cave-inRock, Sunburst, Shelton, and Shawnee did not exhibit growth promotion in response to PsJN under similar conditions. Preliminary result from Cave-in-Rock bioassay indicated that PsJN titers were not sustained after inoculation and were much lower in the non-responsive plants following inoculation.

\section{Discussion}

In the present study, we demonstrated the ability of $B$. phytofirmans PsJN to colonize and promote growth in switchgrass cv. Alamo. Three days following PsJN inoculation, we could clearly visualize bacterial colonization inside the roots under confocal microscopy. The bacterial population inside the roots was initially much higher than that of the leaves and sheaths, and the bacterial endophyte was subsequently translocated vertically to the upper leaves through the leaf sheath. These results were similar to that reported for grapevine [22] and potato [39], where PsJN was transported through the interior vascular system, from root xylem vessels to the upper parts of the plants. This is a critical first step in the endophytic bacteria-plant interaction [40]. We observed significant growth promotion of cv. Alamo by PsJN, under both in vitro and soil conditions. Our study showed total fresh weight and total dry weight of the inoculated plants was increased by $45 \%$ and $55 \%$ respectively compared with the non-inoculated control plants when the inoculated seedlings were grown in vitro and then transferred to soil and grown in growth chamber for one month. Similar results have been obtained in 4gallon pots under our greenhouse conditions. Other studies have reported levels of growth promotion by PsJN, with grapevine showing a 6-fold increase in total biomass [34], and potato showing an approximate 2-fold increase in root and haulm biomass [36] over controls. The mechanism of plant growth by $B$. phytofirmans PsJN has been reported [21] and attributed to the ability
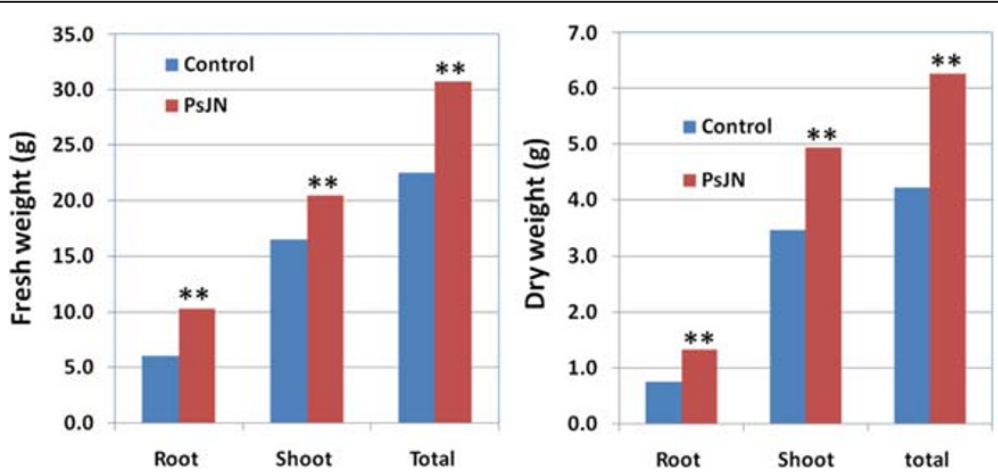

Figure 5 Growth promotion persistence of Alamo in greenhouse by PsJN inoculation. The seedlings were inoculated with PsJN and grown in vitro for one month, then transferred to 4-gallon pot with 5 plants/pot and grown in greenhouse for two months. Dry weight was determined after samples were dried in oven at $65^{\circ} \mathrm{C}$ for one day. Sample number was 25 , and ** means significant difference at 0.01 level between PsJN and control using student T-test. 

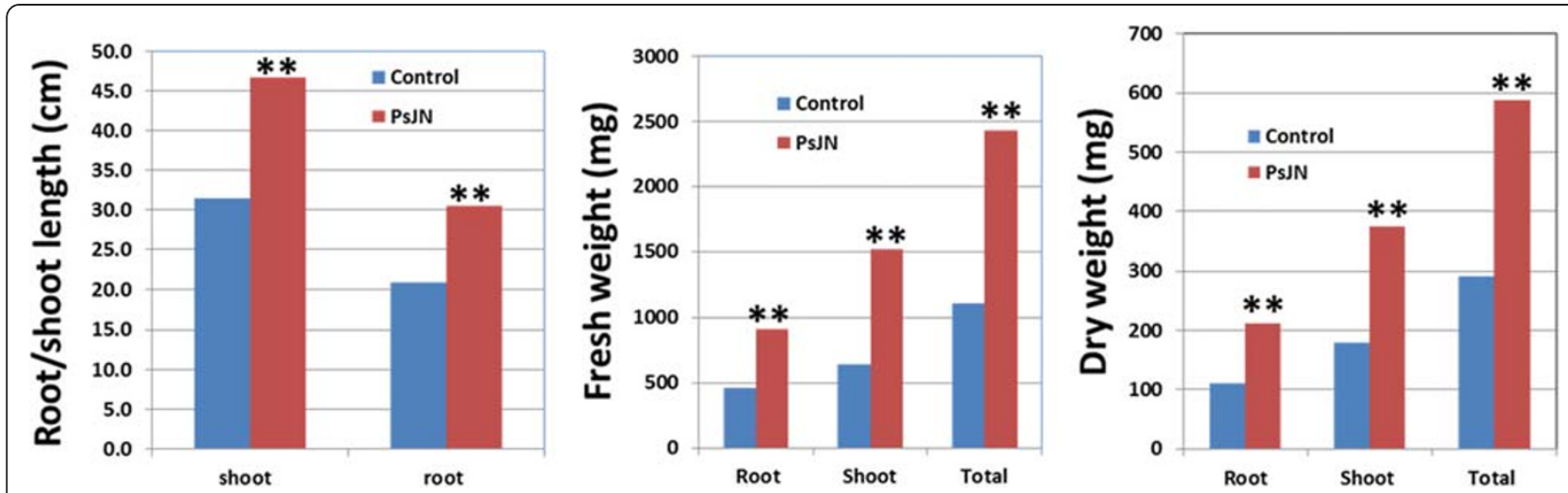

Figure 6 Growth promotion of Alamo by PsJN inoculation in sub-optimal conditions. The seedlings were inoculated with PsJN and grown in vitro for one month, then transferred to 4-gallon pots with 5 plants/pot with unfertilized field soil and grown in the glasshouse under ambient conditions for 2.5 months in the late Fall of 2010. Dry weight was determined after samples were dried in oven at $65^{\circ} \mathrm{C}$ for one day. Sample number was 25, and ** means significant difference at 0.01 level between PSJN and control using student T-test.

of PsJN to produce high levels of ACC deaminase activity, which degrades ACC to ammonia and $\alpha$ ketobutyrate [41], which is a common characteristic of plant growth promoting bacteria. ACC is the precursor to ethylene, a plant stress hormone; hence, the reduced ethylene level in PsJN-colonized plants will promote plant growth. According to the report by Penrose and Glick (2003) [42], ACC activity over $20 \mathrm{nmol} \alpha-$ ketobutyrate $/ \mathrm{h} / \mathrm{mg}$ is sufficient to promote host plant growth, and PsJN has been shown to contain $308 \mathrm{nmol}$ $\alpha$-ketobutyrate/h/mg of ACC deaminase activity [31]. Although several studies have reported the interaction between this endophyte and host plants for growth promotion, most studies have reported in vitro data $[22,27,28,36]$. Our results with unfertilized field soil, in a glasshouse under ambient conditions during the Fall, when the temperature was not optimal for switchgrass growth (Figure 6) implied the potential benefit of switchgrass inoculated with PsJN for growth on marginal lands and sub-optimal growth conditions. Although our results indicate potential benefit of bacterial endophytes in switchgrass under in vitro, growth chamber and greenhouse conditions, much work still needs to be done in assessing growth promotion of switchgrass by endophytes in the field since there is much more competition between endophytes and other microorganisms in addition to many other unfavorable conditions. While our initial studies were carried out with cv. Alamo, we tested the utility of PsJN as a growth-promoting endophyte with other switchgrass cultivars. Our results indicated that specific genotype effects existed, with some genotypes being highly responsive to the growth promotive effects of PsJN, and others not. Similar genotype effects have been reported by others. It was reported that the potato response to PsJN involves some form of genetic control, as some potato cultivars display the beneficial response to the endophyte, while others do not $[35,43,44]$. The typical in vitro phenotype for a strongly responsive cultivar was characterized by a massive, wellbranched root system and after the first 3-4 weeks in
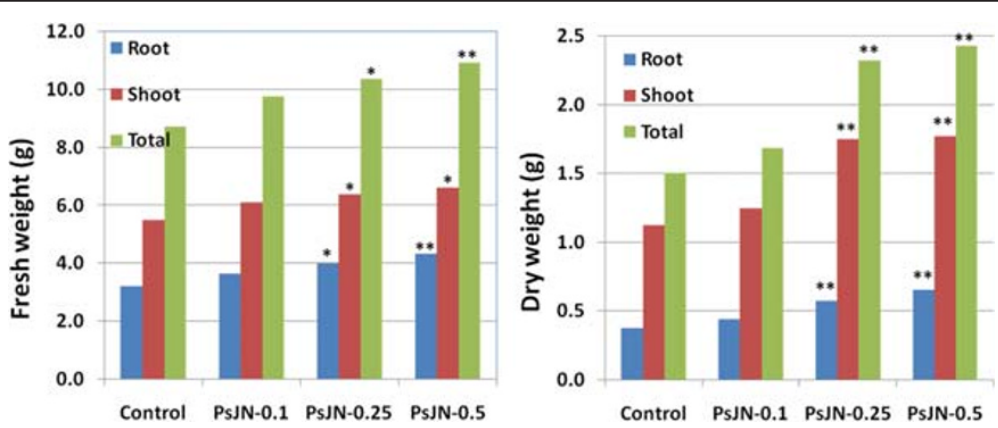

Figure 7 Effects of different concentrations of PsJN on swtchgrass cv. Alamo growth with direct seed inoculation. The surface-sterilized seeds were infected with different concentrations of PsJN and grown in vitro for 17 days, then transferred to 72-cavity trays and grown in a growth chamber for 50 days. * and ${ }^{* *}$ mean significant difference at 0.05 and 0.01 levels respectively between PsJN and control using student T-test. 


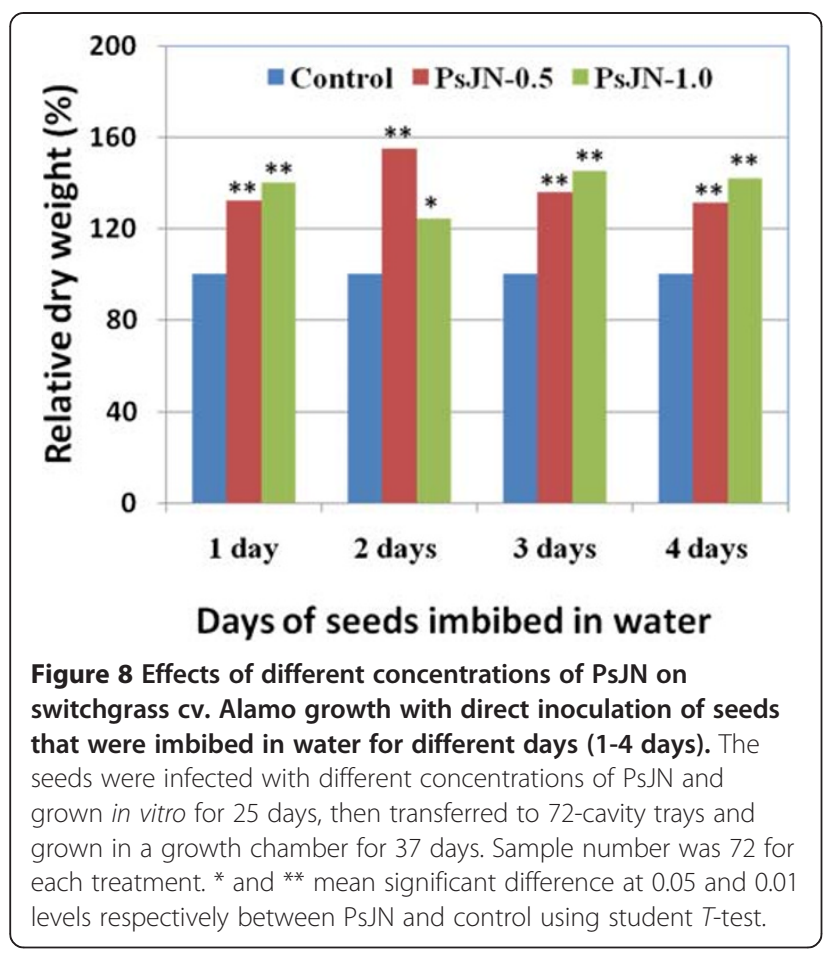

Table 2 Effects of B. phytofirmans PsJN on plant growth in different switchgrass cultivars

\begin{tabular}{|c|c|c|c|c|c|c|}
\hline Cultivars & Treatment & No. plants & Root length $(\mathrm{cm})$ & Shoot length $(\mathrm{cm})$ & Total fresh weight (mg) & PsJN/control (\%) \\
\hline \multirow[t]{3}{*}{ Shawnee } & Control & 24 & 2.3 & 8.4 & 50.1 & \\
\hline & PsJN & 24 & 2.1 & 7.8 & 58.8 & 117.4 \\
\hline & $p$-value ${ }^{b}$ & & 0.2037 & 0.2049 & 0.0717 & \\
\hline \multirow[t]{3}{*}{ Nebraska } & Control & 24 & 1.5 & 10.3 & 40.9 & \\
\hline & PsJN & 24 & 1.5 & 11.6 & 51.9 & 126.8 \\
\hline & $p$-value & & 0.4160 & 0.0656 & 0.0055 & \\
\hline \multirow[t]{3}{*}{ Forestburg } & Control & 34 & 1.6 & 8.6 & 33.7 & \\
\hline & PsJN & 30 & 1.8 & 12.7 & 54.0 & 160.1 \\
\hline & $p$-value & & 0.1986 & 0.0000002 & 0.0000001 & \\
\hline \multirow[t]{3}{*}{ Shelton } & Control & 28 & 3.3 & 14.1 & 117.7 & \\
\hline & PsJN & 28 & 3.0 & 12.0 & 135.3 & 115.0 \\
\hline & $p$-value & & 0.1579 & 0.0067 & 0.0907 & \\
\hline \multirow[t]{3}{*}{ Blackwell } & Control & 28 & 1.4 & 9.9 & 52.6 & \\
\hline & PsJN & 28 & 1.5 & 11.3 & 64.7 & 123.0 \\
\hline & $p$-value & & 0.2970 & 0.0998 & 0.0543 & \\
\hline \multirow[t]{3}{*}{ Sunburst } & Control & 30 & 0.8 & 8.5 & 33.0 & \\
\hline & PsJN & 28 & 0.9 & 10.4 & 26.4 & 80.0 \\
\hline & $p$-value & & 0.2985 & 0.0137 & 0.0731 & \\
\hline \multirow[t]{3}{*}{ Cave-in-Rock } & Control & 33 & 2.8 & 14.7 & 107.8 & \\
\hline & PsJN & 34 & 3.1 & 13.8 & 113.4 & 105.2 \\
\hline & $p$-value & & 0.2317 & 0.4052 & 0.5613 & \\
\hline
\end{tabular}

\footnotetext{
${ }^{a}$ PsJN/control (\%) means total fresh weight of PsJN inoculated plants over that of control plants.
}

culture, the plantlet was developmentally more advanced than the non-bacterized controls. Stems were sturdier, with more lignin deposits around the vascular system, and the plantlets developed more root hairs and more and larger leaf trichomes [43]. We also noticed PsJNinoculated switchgrass plants were developmentally advanced (unpublished data). Such enhancements were not apparent for the poorly-responsive cultivars. We also observed some of these phenotypic differences between PsJN-responsive and non-responsive switchgrass cultivars. Additional work illustrating the genetic control of the beneficial response to the endophyte used monoploid potato lines derived from anther culture of an adapted diploid Solanum phureja clone, BARD 1-3 [44]. The diploid anther donor, BARD 1-3, exhibited a bacterization response comparable to Red Pontiac, while monoploid lines exhibited a response to PsJN ranging from favorable to unfavorable to neutral. The assumption here was that the response range of the monoploid population was due to the segregation of alleles for genes involved in regulating the positive or negative interaction with PsJN.

The potato/PsJN studies have been the most characterized, and carried out with material clonally propagated via nodal sections, in which a single inoculation is sufficient to initiate colonization through the xylem tissue,

\footnotetext{
${ }^{\mathrm{b}} \mathrm{p}$-value means degrees of statistical significance between PsJN treatment and control using student $T$-test.
} 
eventually spreading to the upper leaves [36]. Bacterial levels must reach a threshold population within the plant before they are effective [45] with a direct relationship between plantlet growth enhancement and PsJN colonization of both interior and exterior surfaces [44]. The PsJN colonization profiles for a responsive and poorly responsive cultivar over 8 tissue culture generations revealed bacterial loads one order of magnitude greater for shoot/root surface and interior colonization in the responsive compared to the poorly responsive cultivar. Furthermore, the responsive cultivar exhibited increased colonization over successive generations, while the poorly responsive cultivar exhibited declining bacterial populations over successive generations. We are currently assessing the level of colonization in switchgrass cultivars responsive and non-responsive to PsJN to determine the degree of similarity between switchgrass and potato responses to the endophyte. At present, the mechanisms governing B. phytofirmans PsJN genotypespecificity in growth promotion of switchgrass (and other plants) are unknown, although we are currently using large scale gene expression analyses to determine the differences in the switchgrass molecular responses between differently-responding cultivars. In summary, the results reported here illustrate the ability of B. phytofirmans PsJN to infect and colonize responsive switchgrass (Panicum virgatum) cultivars like Alamo, and to promote plant growth. This study lays the foundation to develop a low input and sustainable switchgrass feedstock production system on marginal lands using this, and other, beneficial bacterial endophytes.

\section{Conclusions}

Results obtained with growth promotion of switchgrass cv. Alamo by B. phytofirmans PsJN under various growth conditions, sub-optimal in particular, indicate the potential for utilization of beneficial bacterial endophyte in switchgrass establishment in the first year and in the development of low input and sustainable switchgrass feedstock production system. In the future, the mechanisms of growth promotion need to be elucidated with molecular biology and functional genomics to develop tools for molecular breeding for beneficial plantmicrobial associations.

\section{Methods}

\section{Plant materials}

Switchgrass (Panicum virgatum L.) cvs. Alamo and Cave-in-Rock seeds were purchased from Warner Brothers Seed Co. (Lawton, OK), and other switchgrass seeds were kindly provided by Dr. Bingyu Zhao (Department of Horticulture - Virginia Tech, Blacksburg, VA). Switchgrass seeds were surface-sterilized by treatment with $70 \%$ ethanol for $2 \mathrm{~min}$, rinsed $3 \mathrm{X}$ with distilled water, de-husked for 30 min with $60 \% \mathrm{H}_{2} \mathrm{SO}_{4}$ with stirring, washed $3 \mathrm{X}$ with distilled water, sterilized with $0.4 \mathrm{M}$ sodium hypochlorite $(50 \%$ commercial bleach solution containing $6 \%$ sodium hypochlorite) containing $0.1 \%$ Triton 100 for $30 \mathrm{~min}$ followed by $5 \mathrm{X}$ rinse with sterile, deionized, distilled water $\left(\mathrm{ddH}_{2} \mathrm{O}\right)$.

\section{Bacterial endophyte and culture conditions}

Burkholderia phytofirmans strain PsJN [31] and its PsJN-GFP derivative [22] were obtained from Dr. Angela Sessitsch (Austrian Institute of Technology, Seibersdorf, Austria). The cultures were streaked on King's B (KB) solid medium as described in [45]. Inoculum was produced by transferring one loop of PsJN from 2-day-old cultures to $5 \mathrm{ml} \mathrm{KB}$ broth in a $15-\mathrm{ml}$ culture tube, followed by incubation at $28^{\circ} \mathrm{C}$ on a shaker (150 rpm) overnight. Five $\mathrm{ml}$ of the overnight PsJN culture was added to $45 \mathrm{ml} \mathrm{KB}$ broth in a $250-\mathrm{ml}$ Erlenmeyer flask and grown to $0.7 \mathrm{OD}_{600}$. Bacterial cells were then collected by centrifugation at $3,500 \mathrm{rpm}$ for $7 \mathrm{~min}$ at $4^{\circ} \mathrm{C}$, and resuspended in PBS buffer $\left(10 \mathrm{mM} \mathrm{NaH} \mathrm{PO}_{4}\right.$ containing $0.8 \% \mathrm{NaC} 1, \mathrm{pH} 6.5)$ after which the $\mathrm{OD}_{600}$ was adjusted with PBS buffer to 0.5 , unless described otherwise.

\section{Seedling inoculation with PsJN and plant growth responses}

Surface-sterilized seeds were germinated in petri-dishes for 7 days at $25^{\circ} \mathrm{C}$, under white fluorescent light $\left(67 \mu \mathrm{mol} \mathrm{m} \mathrm{m}^{-2} \mathrm{~s}^{-1}\right), 16 \mathrm{~h}$ photoperiod, on a switchgrass growth medium consisting of MS salts and vitamins [46], $30 \mathrm{~g} / \mathrm{l}$ maltose and $3 \mathrm{~g} / \mathrm{l}$ phytogel, $\mathrm{pH}$ 5.8. The root tips of the young seedlings were cut prior to PsJN inoculation to facilitate bacterial penetration [45]. For the direct seed inoculation surface-sterilized seeds were placed on wet filter paper for 3-5 days in an incubator at $25^{\circ} \mathrm{C}$ with $16 \mathrm{~h}$ photoperiod (white fluorescent bulbs at $67 \mu \mathrm{mol} \mathrm{m} \mathrm{m}^{-2} \mathrm{~s}^{-1}$ ) followed by soaking in PsJN solution $\left(0.5\right.$ of $\left.\mathrm{OD}_{600}\right)$ for $1 \mathrm{~min}$. Control seedlings/seeds were treated with PBS buffer alone. The treated seedling/seeds were blot-dried with sterile paper towel, placed on switchgrass growth medium in GA7 Magenta vessels (Sigma-Aldrich) containing $50 \mathrm{ml}$ of media and 5 seedlings or germinating seeds per vessel, and grown for one month in the incubator as above. Root and shoot length, and seedling fresh weight were then determined, and the plants transferred to a soil mix composed of $2 / 3$ Miracle-Gro ${ }^{\circledR}$ Potting Mix (Scotts Miracle-Gro Company, Marysville, Ohio) and 1/3 Arabidopsis growing media (Lehle Seeds, Round Rock, Texas). Plants were grown in 72-cavity trays in a growth chamber at a 28 / $22^{\circ} \mathrm{C}$ day/night temperature, $16 \mathrm{~h}$ photoperiod (white fluorescent bulbs at $88 \mu \mathrm{mol} \mathrm{m} \mathrm{m}^{-2}$ ) for 30 days, or 4gallon pots in the greenhouse. 


\section{PsJN colonization}

The plants inoculated with PsJN-GFP were examined under a fluorescent stereomicroscope (Model SZXILLD2-100; Olympus, Tokyo, Japan) equipped with a GFP filter (BP460-490, Olympus, Tokyo, Japan) and the Zeiss 510 laser scanning confocal microscope (LSCM) (Carl Zeiss, Inc., Thornwood, NY) to observe colonization.

For bioassays, the control and PsJN-GFP inoculated plants were surface-sterilized with $0.032 \mathrm{M}$ sodium hypochlorite for $1 \mathrm{~min}$, then washed $4 \mathrm{X}$ with sterile distilled water. Fifty $\mu \mathrm{l}$ of the final wash was plated on solid $\mathrm{KB}$ medium to confirm effectiveness of surface sterilization. Root, leaf and sheath parts were then separated, each weighed, and ground with mortar and pestle in $1 \mathrm{ml}$ sterile distilled water. The homogenates were then centrifuged at $2000 \mathrm{rpm}$ for $3 \mathrm{~min}$, and the supernatant diluted to $1: 10,1: 100$, and $1: 1000$ with distilled water. Fifty $\mu \mathrm{l}$ samples of the serially diluted solutions were spread on solid $\mathrm{KB}$ medium. The plates were incubated for 3 days at $28^{\circ} \mathrm{C}$ in the dark and the number of GFP-positive colonies determined using fluorescence stereomicroscopy as described above.

\section{Competing interests}

The authors declare that they have no competing interests.

\section{Authors' contributions}

SK and SL conducted experiments and drafted the manuscript. GH carried out confocal imaging and data analysis and reviewed the manuscript. CM $\mathrm{JN}$ and BF designed experiments and wrote the paper with input from all authors. All authors read and approved the final manuscript.

\section{Acknowledgements}

This work was funded through Special Grants (2003-38891-02112, 2008-3889119353 and 2009-38891-20092) and HATCH funds (Project No. VA-135816) from the United States Department of Agriculture, the Office of Science (BER), U.S. Department of Energy for Plant Feedstock Genomics for Bioenergy Program (DE-SC0004951), and operating funds from the Commonwealth of Virginia to the Institute for Advanced Learning and Research.

\section{Author details}

${ }^{1}$ Institute for Sustainable and Renewable Resource, Institute for Advanced Learning and Research, 150 Slayton Ave, Danville, VA 24540, USA. ${ }^{2}$ Department of Horticulture, Virginia Polytechnic Institute and State University, Blacksburg, VA 24601, USA. ${ }^{3}$ Department of Forest Resources and Environmental Conservation, Virginia Polytechnic Institute and State University, Blacksburg, VA 24601, USA. ${ }^{4}$ The Dewel Microscopy Facility at the College of Arts and Sciences, Appalachian State University, Boone, NC 28608, USA

Received: 26 March 2012 Accepted: 10 May 2012

Published: 30 May 2012

\section{References}

1. Hamelinck CN, Hooijdonk DV, Faaij AP: Ethanol from lignocellulosic biomass: techno-economic performance in short-, middle-, and longterm. Biomass Bioenergy 2005, 28:384-410

2. Erahin ME, Gomec CY, Dereli RK, Arikan O, Ozturk I: Biomethane production as an alternative bioenergy source from codigesters treating municipal sludge and organic fraction of municipal solid wastes. J Biomed Biotechnol 2011, 201(1):951043. doi:10.1155/2011/951043.

3. Sissine F: Energy Independence and Security Act:; 2007 [http://www.energy.senate gov/public/index.cfm/files/serve?File_id=82061 c68-eef5-4fc3-81b6-ecd569a1d8a3].
4. National Biofuels Action Plan: 2008 [http://www1.eere.energy.gov/biomass/ pdfs/nbap.pdf].

5. Sanderson M, Adler PR, Boateng AA, Casler MD, Sarath G: Switchgrass as a biofuels feedstock in the USA. Can J Plant Sci 2006, 86:1315-1325.

6. McLaughlin SB, Kszos LA: Development of switchgrass (Panicum virgatum) as a bioenergy feedstock in the United States. Biomass Bioenergy 2005, 28:515-535

7. Hill J, Nelson E, Tilman D, Polasky S, Tiffany D: Environmental, economic, and energetic costs and benefits of biodiesel and ethanol biofuels. Proc Natl Acad Sci USA 2006, 103:11206-11210.

8. Humphreys MO: The contribution of conventional plant breeding to forage crop improvement. Saskatoon: Proceedings of the 18th International Grassland Congress; 1999

9. Liebig MA, Johnson HA, Hanson JD, Frank AB: Soil carbon under switchgrass stands and cultivated cropland. Biomass Bioenergy 2005, 28:347-354.

10. McLaughlin SB, Ugarte DGLT, Garten CT, Lynd LR, Sanderson MA, Tolbert VR Wolf DD: High-value renewable energy from prairie grasses. Environ $\mathrm{SCi}$ Technol 2002, 36:2122-2129.

11. Dyer JM, Mullen RT: Engineering plant oils as high-value industrial feedstocks for biorefining: the need for underpinning cell biology research. Physiol Plant 2008, 132:11-22.

12. Sturz AV, Christie B, Nowak J: Bacterial endophytes: potential role in developing sustainable system of crop production. Crit Rev Plant Sci 2000, 19:1-30.

13. Berg G: Plant-micro interactions promoting plant growth and health: perspectives for controlled use of microorganisms in agriculture. Appl Microbial Biotechnol 2009, 84:11-18.

14. Mei C, Flinn BS: The use of beneficial microbial endophytes for plant biomass and stress tolerance improvement. Recent Patents on Biotechnol 2010, 4:81-95

15. Funk CR, White RH, Breen JP: Importance of Acremonium endophytes in turf-grass breeding and management. Agric Ecosyst Environ 1993, 44:215232

16. Ghimire SR, Charlton ND, Craven KD: The mycorrhizal fungus, sebacina vermifera, enhances seed germination and biomass production in switchgrass (Panicum virgatum L). Bioenergy Res 2009, 2:51-58.

17. Ghimire SR, Charlton ND, Bell JD, Krishnamurthy YL, Craven KD: Biodiversity of fungal endophyte communities inhabiting switchgrass (Panicum virgatum $\mathrm{L}$ ) growing in the native tallgrass prairie of northern Oklahoma. Fungal Diversity 2010, 47:19-27.

18. Khan SA, Hamayun M, Yoon H, Kim HY, Suh SK, Hwang SK, Kim JM, Lee IJ, Choo YS, Kong WS, Lee BM, Kim JG: Plant growth promotion and Penicillium citrinum. BMC Microbial 2008, 8:231-240.

19. Nowak J, Mei C, Lowman S, Zhao B, Seiler J, Flinn B: Development of switchgrass (Panicum virgatum L.) for marginal lands based on genotypic compatibility with beneficial bacteria[abstract]. Dalian: In First Annual World Congress of Bioenergy; 2011:25-29.

20. Welbaum G, Sturz AV, Dong Z, Nowak J: Managing soil microorganisms to improve productivity of agroecosystems. Crit Rev Plant Sci 2004, 23:175-193.

21. Compant S, Duffy B, Nowak J, Clément C, Barka EA: Use of plant growthpromoting bacteria for biocontrol of plant diseases: principles, mechanisms of action and future prospects. Appl Environ Microbiol 2005, 71:4951-4959.

22. Compant S, Reciter B, Sessitsch A, Nowak J, Clement C, Barka EA: Endophytic Colonization of Vitis vinifere L. by Plant Growth-Promoting Bacterium Burkholderia sp. Strain PsJN. Appl Environ Microbiol 2005, 71:1685-1693

23. Glick BR, Penrose DM, Li J: A model for the lowering of plant ethylene concentrations by plant growth promoting bacteria. J Theor Biol 1998, 190:63-68.

24. Glick BR: Bacterial ACC deaminase and the alleviation of plant stress. Adv Appl Microbiol 2004, 56:291-312.

25. Mattos KA, Pádua VLM, Romeiro A, Hallack LF, Neves BC, Ulisses TMU, Barros CF, Todeschini AR, Previato JO, Mendonça-Previato L: Endophytic colonization of rice by the dizaotrophic bacterium Burkholderia kururiensis and its ability to enhance plant growth. An Acad Bras Cienc 2008, 80:477-493.

26. Arshad M, Frankenberger WT: Microbial production of plant hormones Plant Soil 1991, 133:1-8. 
27. Lazarovits G, Nowak J: Rhizobacteria for improvement of plant growth and establishment. Hortscience 1996, 32:188-192.

28. Conn KL, Nowak J, Lazarovits G: A gnotobiotic bioassay for studying interactions between potatoes and plant growth-promoting rhizobacteria. Can J Microbiol 1997, 43:801-808.

29. Barka EA, Belarbi A, Hachet C, Nowak J, Audran JC: Enhancement of in vitro growth and resistance to gray mould of Vitis vinifera co-cultured with plant growth-promoting rhizobacteria. FEMS Microbiol Lett 2000, 186:91-95.

30. Nowak J, Asiedu SK, Lazarovits G: Enhancement of in vitro growth and transplant stress tolerance of potato and vegetable plants co-cultured with a plant growth promoting rhizobacterium. In Ecophysiology and Photosynthetic In Vitro Cultures. Edited by Carre F, Chagvardieff P. Aix-enProvence: CEA; 2003:173-180.

31. Sessitsch A, Coenye T, Sturz AV, Vandamme P, Barka EA, Salles JF, Elsas JD, Faure D, Reiter B, Glick BR, Wang-Pruski G, Nowak J: Burkholderia phytofirmans sp. nov., a novel plant-associated bacterium with plantbeneficial properties. Int J Syst Evol Microbiol 2005, 55:1187-1192.

32. Wang K, Conn K, Lazarovits G: Involvement of quinolinate phophoribosyl transferase in promotion of potato growth by a Burkholderia Strain. Appl Environ Microbiol 2006, 72:760-768.

33. Weilharter A, Mitter B, Shin MV, Chain PSG, Nowak J, Sessitsch A: Complete genome sequence of the plant growth-promoting endophyte Burkholderia phytofirmans strain PsJN. J Bacteriol 2011, 193:3383-3384

34. Barka EA, Nowak J, Clément S: Enhancement of chilling resistance of inoculated grapevine plantlets with a plant growth-promoting rhizobacterium, Burkholderia phytofirmans strain PsJN. Appl Environ Microbiol 2006, 72:7246-7252

35. Bensalim S, Nowak J, Asiedu SK: A plant growth promoting rhizobacterium and temperature effects on performance of 18 clones of potato. Am J Potato Res 1998, 75:145-152.

36. Frommel MI, Nowak J, Lazarovits G: Growth enhancement and developmental modification of in vitro grown potato (Solanum tuberosum spp. tuberosum) as affected by a nonfluorescent Pseudomonas sp. Plant Physiol 1991, 96:928-936.

37. Sharma V, Nowak J: Enhancement of verticillium wilt resistance in tomato transplants by in vitro co-culture of seedlings with a plant growth promoting rhizobacterium (Pseudomonas sp. strain PsJN). Can J Microbiol 1998, 44:528-536.

38. Barka EA, Gognies S, Nowak J, Audran J, Belarbi A: Inhibitory effect of endophyte bacteria on Botrytis cinerea and its influence to promote grapevine growth. Biol Control 2002, 24:135-142.

39. Reiter B, Pfeifer U, Schwab H, Sessitsch A: Response of endophytic bacterial communities in potato plants to infection with Erwinia caratovora subsp. atroseptica. Appl Environ Microbiol 2002, 68:2261-2268.

40. Whipps JM: Microbial interactions and biocontrol in the rhizosphere. $J$ Exp Bot 2001, 52:487-511.

41. Long HH, Schmidt DD, Baldwin IT: Native bacterial endophytes promote host growth in a species-specific manner; phytohormone manipulations do not result in common growth response. PLoS One 2008, 3:e2702.

42. Penrose DM, Glick BR: Methods for isolating and characterizing ACC deaminase-containing plant growth promoting rhizobacteria. Physiol Plant 2003, 118:10-15.

43. Nowak J, Asiedu SK, Bensalim S, Richards J, Stewart A, Smith C, Stevens D, Sturz AV: From laboratory to applications: challenges and progress with in vitro dual cultures of potato and beneficial bacteria. Plant Cell Tiss Org Cult 1998, 52:97-103.

44. Nowak J, Veilleux RE, Nowak J, Turgeon S: Priming for transplant stress resistance in in vitro propagation via plantlet bacterization. Acta Hort 2007, 748:65-75

45. Pillay VK, Nowak J: Inoculum density, temperature, and genotype effects on in vitro growth promotion and epiphytic and endophytic colonization of tomato (Lycopersicon esculentum L.) seedlings inoculated with a pseudomonad bacterium. Can J Microbiol 1997, 43:354-361.

46. Murashige T, Skoog F: A revised medium for rapid growth and bioassays with tobacco tissue cultures. Physiol Plant 1962, 15:473-497.

doi:10.1186/1754-6834-5-37

Cite this article as: Kim et al.: Growth promotion and colonization of switchgrass (Panicum virgatum) cv. Alamo by bacterial endophyte Burkholderia phytofirmans strain PsJN. Biotechnology for Biofuels 2012 5:37.

\section{Submit your next manuscript to BioMed Central and take full advantage of:}

- Convenient online submission

- Thorough peer review

- No space constraints or color figure charges

- Immediate publication on acceptance

- Inclusion in PubMed, CAS, Scopus and Google Scholar

- Research which is freely available for redistribution 